\title{
BOLOGNA CITY BRANDING PROJECT.
}

\section{PROJETO DE BRANDING TERRITORIAL DE BOLOGNA.}

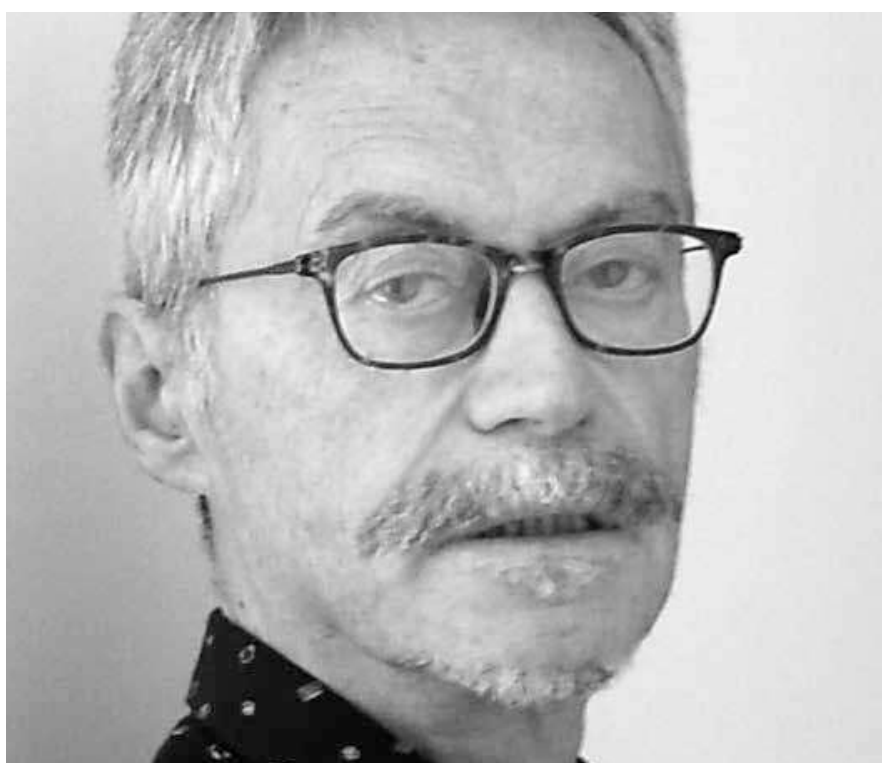

\section{Roberto Grandi}

Dottore in Scienze Politiche University of Bologna

Department of Political and Social Sciences Uni-

versity of Bologna

Professor

roberto.grandi@unibo.it

\section{ABSTRACT}

In the international scenario the process of economic, social and cultural globalization has increased competition among cities and territories, stressing necessity to build a territorial brand able to express the unique and distinctive positioning of that territory.

The first part of this paper deepens the theoretical framework for understanding the development of the place branding and city branding.

The second part investigates the development of the Bologna City Branding Project. Analysis of the perception of Bologna's image was the starting point of construction of the identity of the city, which constitutes the substance preceding the brand.

The further step was characterized by the identification of the logo and the identification concept of the Bologna brand.

The last phase proposes to reposition the city through valorisation, communication and management of the city branding seen as strategic communication. 


\section{KEYWORDS}

Place marketing. Place branding. City Branding.

\section{PALAVRAS-CHAVE}

Marketing Territorial. Branding Territorial. Branding de Cidades

\section{INTRODUCTION}

In the international scenario the process of economic, social and cultural globalization has induced an increase in competition among cities and territories that is mainly manifested in the increasing necessity to clearly define the identification features and positioning of cities and territories with the objective of constructing a territorial brand able to attain greater visibility, to increase the capacity for attraction and to improve the perceived image through a plurality of planning and communication actions.

\section{PLACE MARKETING}

The promotion of territories by public institutions and private organizations is a phenomenon that we already find in the $19^{\text {th }}$ century, but it was more or less in the 1970s that places became the object of application of marketing techniques, as a result of the enlargement of the spheres of application of marketing to non-profit organizations, the social sphere and the world of ideas.

Indeed, it was in 1976 that place marketing - meaning all the activities planned for creating "a positive attitude and behaviour towards geographical places" (1) - was identified as a new challenge for marketing.

As long ago as the 1980s marketing techniques were applied with some continuity to processes of repositioning and valorisation of territories when, following significant processes of deindustrialization, many European cities developed important processes of urban regeneration, mainly based on policies of reuse of abandoned buildings in relation to a new process of development hinging on the economy of knowledge, creativeness and culture. (2)

Until the early 1990s place marketing was mainly manifested as the sale and promotion of places, favoured by a more and more entrepreneurial 
approach to the problems of the territory adopted by an increasing number of public local administrators.

Within place marketing two specializations developed: tourism marketing, on one side, and city marketing, on the other, characterized by different though complementary fields of action and different targets. In both cases the objective was promotion of the territory with marketing techniques to increase its attractiveness.

Towards the end of the 1990s it became clear that the objective of city marketing, i.e. winning the competition among cities through the offer of territories promoted as products able to respond in the best possible way to the demands of "place users", often attained short-term successes that failed to be consolidated in the long term. The fact is that a tactical approach prevailed, to the detriment of a strategic formulation, which, to be enacted, had to go beyond actions simply responding to the demands of the tourist market, thanks to the adoption of new paradigms of analysis or, at least, of new action tools and methodologies. The analogy between the promotion of products and services and the promotion of places appeared less and less suited to the latter in that places are very complex entities that have difficulty in being perceived and presented as commodities to be offered to the different target types.

\section{BRAND AND BRANDING}

It was indeed in the years mentioned that the marketing-oriented approach was sometimes integrated with and sometimes replaced by an approach privileging the concept of brand.

The brand furnishes the substance of and gives meaning to the strategy of the enterprise and its culture and, accordingly, has a central organizational function, in that it constitutes the component of greatest value of an enterprise or an institution.

From the communicative point of view, the brand (3) can be considered as a mechanism of valorisation of the hallmark that enterprises enact through "construction of meanings" that in the mind of different publics help to define the unique and distinctive positioning of an enterprise or a territory. For some time now organizations and institutions have been constructing communicative strategies able to increase the value of the brand starting 
from the definition of their own identity.

Branding, which some reductively equate with the visual identification of the enterprise, involves a "vast sphere of the enterprise strategy, the behaviour and motivation of the consumer and stakeholders, internal and external communications, ethics and objectives [...] it is used for navigating through the complex network of relationships between the personality of the enterprise, the products or services - the brand in itself - and the people that produce and distribute them, like those who consume them and come into contact with them." (4)

From a more operational point of view branding can be defined as the process of planning and communication of the identify features to cause the image perceived by the various reference publics to correspond as closely as possible with the expected identity (5): when the perceived image corresponds to the expected one the communication and initiatives undertaken by the city are considered effective.

The fact is that defining the identification features that make reference to the tangible and intangible attributes constitutes the first step in any action of communication of a territory. We can maintain that definition of the identification features is a sort of precondition of any potentially effective communicative process. A proof of this is the fact that there are cases in which the poor effectiveness of communication is imputed to the communicative choices made, when it is instead a consequence of an ambiguous or unclear choice of the basic characters of the identity to be transmitted.

The conclusive moment of the process of construction of a brand its moment of truth - is given by the image that the various reference publics have of the brand. This image is influenced by all the experiences, information, impressions, opinions, stories, prejudices, clichés on the tangible and intangible characteristics that individuals build up - directly or indirectly, consciously or unconsciously - on a certain product, service or territory.

\section{PLACE BRANDING}

If place marketing privileged the targets external to the city, to whose demands for places it tried to give adequate answers, place branding also keeps in mind the internal targets of the city itself. Attainment of the best- 
known and most attractive objectives, proper to place marketing, must, in my opinion, be preceded by the definition of the identification features of a territory and its positioning or repositioning.

This transition from place marketing to place branding has also been favoured by some specific characteristics of territories, first of all by the fact that their identity does not coincide with the sum of the characteristics of its specific and single tangible components. In this connection, there is a difference between place branding and the promotion of single products of the territory like different tourist destinations, opportunities for investment, festivals, the main events, and so forth. Destination branding, used to indicate the current forms of tourist promotion, differs from place branding in that "tourism is only one of the components of the city, nation or region and unlike the nation (or city) seen as a whole, is a 'product' that has to be 'sold' on the global market [...] the components of a territory can be promoted, even sold, but not the nation or the city [...] the nation does not usually have a single market or propose a single offer and in such conditions promotion becomes difficult and useless." (6)

The characteristics that differentiate places from products and services, which are the prevalent object of marketing activity, are four. (7) In the first place there is the bigger variety of consumers characterized by major plurality of needs and desires: the different types of tourists (from business to religious ones, from cultural to congressional ones), skilled workers, students, investors, talents and residents. Secondly, there is the complexity of the "place product", which often makes reference to a set of spaces that are interrelated, on both the regional and the municipal scale. Thirdly, there is the perception that people have of places, which includes more numerous variables than the majority of products and services, in that experience of a place depends on both tangible and intangible variables: not only the physical, historical, monumental and urban features of a place, but also the relationships among people, historical memory, symbols and social relationships. Fourthly, there is the political and administrative sphere, which significantly conditions the political decision-making process that influences the development of territories.

The perceived images of a territory are therefore a social construction based on the opinion that the various publics have of the place and that fulfils two main functions. 
The perceived image of a territory, on one side, constitutes the framework of meaning within which we interpret what concerns that particular territory, and on the other it is what influences the expectations that the different publics have in relation to that territory and to which the territories have to respond adequately(8). In other words, the same event will be perceived in a different way depending on whether it takes place in one city or another and accordingly will respond to different expectations. For example, visitors to cities like Venice and Florence come to these cities with an already acquired image of them as cities of art and culture of global importance; this image constitutes that framework inside which visitors give meaning to the single moments of their visit and compare them with the high expectations that they have. By contrast, visitors that go to Bologna - a city of limited international fame - do not have a preformed image of the city, and therefore come with limited expectations. That is the reason why, as we will see subsequently, in the majority of people visiting Bologna produces a sense of pleasant surprise due to the richness of the cultural, artistic and urbanistic fabric, about which they did not have any expectation.

But why such insistence on the role played by the image of a territory perceived by the different reference publics? The answer is that these are perceptions that, influencing the positive or negative attitude towards a territory, conditions people's behaviours towards a particular city: in the case of external publics, they influence intentions to visit it or to invest capitals in it; in the case of internal publics like residents, they influence their level of civic sense of belonging. A territory in which the residents have little pride and sense of belonging towards the territory communicates negative feelings that also inevitably influence perception by external publics and its reputation.

The analysis of the images of a city perceived by the different reference publics (including residents) gives us information, in my opinion, which is central to identifying the perceived positioning and succeeding in carrying out possible actions for repositioning.

Four different ways of considering the image can be distinguished. (9)

The brand image makes reference to the "reputation seen as an external phenomenon, a cultural one that is not under the direct control of the 'holder of the brand'." The brand identity coincides instead with the visual identity of the brand. Brand equity implies that "the reputation is that asset of great 
value that requires to be managed, measured, protected and nurtured." The brand purpose makes reference to the management of the brand seen as an "internal project that unifies groups around a common strategic vision."

In the case of the perceived image of a city, reference is made (10) to two different types of communicative process: those directly managed by the city and those produced and circulated by other entities. The first case includes those actions that do not have a primary communicative objective, but have communicative consequences that influence perception of the city: the organization of the cityscape (from urban planning to public spaces), the operation of infrastructures (both those correlated with the accessibility of the city and cultural ones, business ones, etc.), the political and administrative process, the services and the planned events. Secondly, the communications put in place by the different cities through real communicative tools as in the case of promotion campaigns, presence in social media, relations with the mass media. Among communications not controlled by the city that influence its perceived image we place all the other variables that can influence the perception of a place: the stories, which more and more often use images, the media and those that visitors and residents post online, the communications of other competing cities, the experiences and the judgments of the influential publics, and word of mouth.

Place branding is affirmed as a concept that includes others inside it in relation to different spatial variables: nation branding, region branding and city branding.

\section{CITY BRANDING}

In the case of city branding one starts from the need to give a city identification features that make reference, first of all, to its own vision.

City branding includes "creation of an identity with its specific experiential values, original and impossible to copy. This makes reference to some elements like structures, planning, functions, the set of actions and activities that characterize the image of the city, events and, lastly, the chemistry of the populations that activate these variables." (11)

In my opinion any process of city branding that starts from the need to redefine the identification features and to reposition cities, often as a reaction to the altered global context, should develop first of all by 
recovering the narrations of the city told by the different subjects internal and external to the city itself. These are narrations that are often implicit in attitudes and behaviours towards the city and in the city, above all on the part of residents and city users, and narrations expressed explicitly above all by visitors. Indeed, thanks to the development of the social media in the last few years there has been an increase in the channels through which people - as happened in the case of the 20,000 texts associated with the word "Bologna" that appeared in the different social media in the months of December 2012 and January 2013 - can express what they think about a city, turning their individual and group experiences into narrations.

This plurality of narrations regarding the same city, as was verified in the phase of research on the perception of the city of Bologna by different segments of people, represents that raw material to use and interpret for building narrations of the brand that are not only pertinent but also credible and effective.

\section{BOLOGNA CITY BRANDING PROJECT(12)}

The Bologna City Branding project came into being for the purpose of increasing the effectiveness of Bologna's territorial marketing policies, both defining the positioning that the city wishes to attain in a metropolitan dimension and identifying the most suitable strategies to communicate the narration of this positioning to the different reference publics at a local, national and international level.

The desire for this action is translated into creating a specific identity for Bologna that is perceived by visitors and in which city dwellers recognize themselves.

\subsection{THE CONSTRUCTION OF THE BOLOGNA BRAND THROUGH QUANTITATIVE AND QUALITATIVE RESEARCHES}

Analysis of the perception of Bologna's image at a local, national and international level was in fact the first phase of the process of construction of the identity of the city, which constitutes the substance preceding the brand.

This phase developed through three different types of researches.

An original research with a questionnaire to a sample constituted by 
visitors to Bologna in the last ten years. Of the 405 questionnaires compiled, 250 were compiled in English and 155 in Italian.

A second research summed up the results of preceding researches on the perception of Bologna by residents.

A third investigation used the knowledge mining technology to make a Grammatical, Logical, Semantic and Sentiment analysis of the 20,000 or so posts on the web in the period December 2012-January 2013 containing the word "Bologna."

What words, arguments and feelings are associated with the city of Bologna on the web? How do Italians and foreigners speak of Bologna? How is the city described and presented by those who have visited it?

The method used for measuring the perception of the Bologna brand was the one called "Sentiment and Knowledge Mining": a consolidated technique making it possible to manage automatically a large set of texts that cannot be processed with traditional techniques, extracting from them the most important information and making it available in the decision process (13).

Very significant were the texts in English, posted by tourists that had visited the city and desired to share and recount their experience. The most important common names used make reference to some main semantic fields that are very important for determining the perception of the Bologna brand. Time, city and day refer to the time spent in the city, which is generally very short. Food, restaurant, ice cream and pasta belong instead to the semantic field of food, which is recognized to be a Bologna highpoint.

Friend/friendly is well able to characterize the semantic field of the atmosphere that one breathes in the city, while students and University indicate other semantic fields that characterize the experience of a visit to Bologna: the presence of the university and the students in the city's historic area, the vivacious cultural life and evening entertainments.

In general it can be affirmed that:

The association of the city of Bologna with food is very significant. Food is much appreciated both in restaurants and purchased in the typical openair markets Many descriptions also make reference to the philosophy of slow food.

Tasting is associated both with ice cream and with wine. Ice cream is 
considered a handmade product, good, fresh and delicious and is perceived as part of Italian culture.

The perceived image of the city is determined by both tangible and intangible characteristics. Foreigners appreciate the kindness and the accent of the people of the place, although at times it is even excessive. Tourists also appreciate the family atmosphere of the city, which makes them feel at home.

The perception of the city atmosphere is influenced by how the tourist feels while he/she is walking around the city. Tourists love to wander without having a clear destination, walking along the streets, which they find crowded and narrow but also dirty. This wandering about is facilitated by the structure of the historic area and by its maze of streets that is pleasant to explore without hurry and free from schedules.

Foreigners associate Bologna with music and musicians and they listen to music live both at the numerous concerts and in the street, as well as in the dedicated places. This association legitimises Bologna's nomination by Unesco as a city of music.

The presence of verbs, adjectives and adverbs like find, share, love, like, different, unbelievable, interesting and also associated with Bologna is correlated with the fact that Bologna's widespread image is its not being considered one of the main Italian tourist destinations. The fact that Bologna is not perceived as a markedly touristic city lowers expectations and increases the possibility that visitors will be positively struck by it. In this connection, visitors often emphasize their pleasant surprise at discovering an unknown city. Bologna is perceived as a set of different cities in a single city and it is considered really also something else. It is perceived as a hidden jewel, and as a secret to share, thanks also to the magic of the porticos.

This analysis made it possible to identify how this perception influenced the reputation of the city of Bologna on the Web.

Thanks to the use of investigation techniques, both qualitative and quantitative, it was possible to define a sufficiently representative map of the narrations that constituted the perceived image of the city.

On this map there were superimposed the narrations that emerged in the seven focus groups run between January and February 2013 centring on the definition of the expected image (aspirational brand identity) on the part of witnesses representative of the various stratifications of city dwellers. 
Between April and May 2013 \#Caroamicotiinvito was activated, that is to say an online contest to collect the stories of the city with the words and images of city dwellers.

The results of all these researches, contextualized in the conclusions of the Metropolitan Strategic Plan approved in the same period, led to choice the identification features and narrations in which the city, seen as a collective subject, recognizes itself, and which concluded the first phase of the process of city branding, i.e. the phase of construction of the Bologna brand.

The indications deriving from it were taken as a guide for addressing the subsequent repositioning of the city enacted in the second phase of the process of city branding, the one centring on communication and management of the brand at a local, national and international level.

\subsection{INTERNATIONAL CONTEST FOR LOGO AND PAYOFF}

During the past decade cities have been asking themselves how to find a logo that, at the same time, expresses the complexity and the multiplicity of the identifying traits of a city and its uniqueness.

In order that a logo is creative and effective it must have a number of characteristics. First of all it must be distinctive and unique, to express the strong identity of the city with a sign of quality that is capable of attracting attention and which is out of the box, that is, a sign conceived by lateral thinking.

The claim I Amsterdam has been developed from the word Amsterdam. In order to express the openness of the city, Copenhagen decided to use the adjective open inside the word Copenhagen and changes colour and design depending on the concepts that describe the city of Copenhagen at that given moment. Melbourne has chosen an attractive geometric $M$ which changes in shape, content and colour depending on what kind of description is desired for the city. The logo of Bahrain moves away from rigid logos. It is a logo that changes shape and colour depending on the sectors it wishes to represent. Until the Bologna logo was created, the logo which was the most dynamic was that of Nordkyn, an area made up of two cities in the north of Norway, the claim for which is Where Nature Rules. How could the concept that nature truly rules in Nordkyn be communicated? If you visit the site Visit Nordkyn you will see that this logo changes shape and colour as the wind 
and temperature conditions change in the area.

The transition from the first to the second phase was characterized by the identification of the logo and the identification concept of the Bologna brand on the basis of the results of the research in the first phase, summed up in the briefing that orientated the International Contest for the logo and payoff of the city of Bologna reserved for single professionals involved in graphics, design and visual communication.

Analysing research on Bologna's perceived image it was possible to define a briefing for the city branding process.

$\begin{array}{cccccc}\text { Bologna is not } & \text { a } & \text { classical Italian } & \text { tourist } \\ \text { city comparable } & \text { to } & \text { Florence } & \text { and } & \text { Venice. }\end{array}$ Not living on mass tourism, the city is appreciated by visitors coming for pleasure or business. In it they recognize a particular serendipity; there is a tangible atmosphere that is reassuring and pleasantly relaxing, making people "feel at home."

As a consequence among the elements qualifying Bologna's repositioning present in the briefing there emerged the indication of the city as a "real city" with a contemporary, vital and experimental image, not a historicized and museum one but one in which the visitor does not feel treated like a tourist, and instead is put in a condition to have a personal experience not enclosed in forced pathways, but inspired by his or her curiosity to discover this "hidden jewel" through open expressive codes that can be customized. In the briefing is expressed the necessity to identify a logo and concept able to arouse in people all over the world curiosity and the desire to come to Bologna because this is an open, innovative and welcoming city in which it is possible to have experiences and authentic emotions according to one's own inspirations.

\subsection{THE WINNING PROJECT : A NEW ALPHABET}

The graphic project that won among the 504 proposals from various countries was done by Matteo Bartoli and Michele Pastore.

The graphic project winner of the international competition can be considered the first co-generative logo of a city. Bartoli and Pastore sought an appropriate visual "translation" of the most significant characteristics of the repositioning of the city, constructing a graphic 
system that could give the biggest plurality of subjects the capacity to contribute - even without having specific competences - to the construction of the visual identity of the city of Bologna: an inclusive and welcoming open code.

Bartoli and Pastore designed a system of writing replacing the graphemes of the Latin alphabet with abstract characterising signs. There was thus designed a new alphabet of geometric signs, based on five signs to be found in the tangible historical memories of the city of Bologna: the fact is that the forms freely take up some figurative archetypes like the octagonal ring of walls around the city, the brick mosaic in the courtyard of the Santo Stefano Basilica, the cross in the old coat-of-arms of the City Council, the gonfalon of the city and the lily in the Rocchetta Mattei decorations. With these forms/letters it is thus possible "to write" any concept referable to the city, including every physical or abstract, general or personal characteristic that one wishes to associate with Bologna.

These geometric shapes led to the creation of an alphabet with each letter corresponding to a shape that refers to one of the five archetypes chosen. (Figure 1).

Figure 1: Alphabet

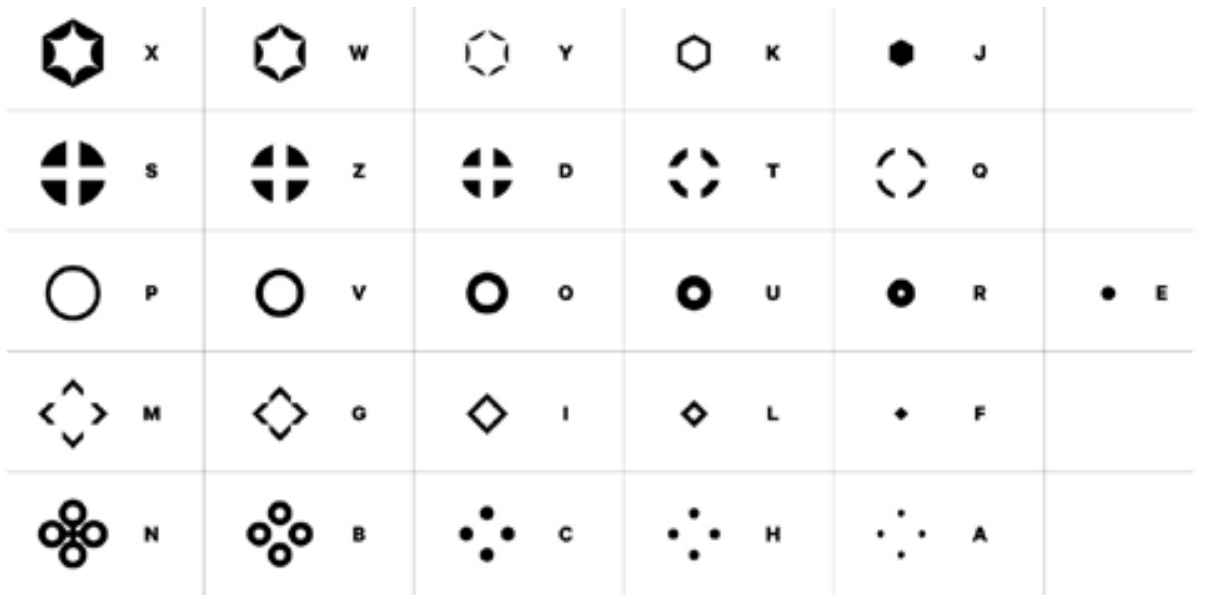

Source: Image from the autor.

Thus a new way of writing was created. The composition rules are simple. You can decide on the nature of the city and write the word letter by letter, the graphic symbol corresponding to that nature will appear.

In fact the geometric shapes follow a system, a "code" of writing: they 
are positioned concentrically, superimposed in transparency according to fixed proportions, thus producing composite figures, marks. Below the word typed is set the claim "is Bologna". In this way the structure "[word/concept] is Bologna" produces a narration of the city.

Whoever has or feel responsibility for communication of the Bologna brand can each time promote those values, concepts and projects that are the story of the positioning of the city, whose graphic sign will be different every time, but always recognizable, and therefore effective, as belonging to same family of logos.

The construction of Bologna's visual identity is thus projected into a new and partly unexplored dimension. It is not only an adaptive and flexible system of identity, but - perhaps for the first time - also a participatory one.

With the tools for generation of free and available logos online (the web platform is currently being set up but an explanatory beta version is available at the address www.ebologna.it), anyone can be an active part of the process, creating, alongside creations by the people and bodies institutionally responsible for promotion of the city, their own personal "fragment" of Bologna's visual identity.

The accumulation over time of this set of signs and concepts, left by city dwellers or by visitors passing through, will enrich Bologna's positioning in a collective and sincere story of the city.

\subsection{COMMUNICATING AND MANAGING THE BRAND}

The second phase of the Bologna City Branding project, made possible by the choice of the generative logo of the city and the concept, proposes to reposition the city through valorisation, communication and management of the brand.

This phase will keep the city of Bologna busy in the next few years, takes on the characteristics of city branding seen as strategic communication, as is illustrated in the document CityLogo, innovative place brand management. (14)

In this connection, considering city branding as strategic communication corresponds more closely to the "simple but important ambition of strengthening local identities by positioning cities more clearly, increasing their visibility." This objective is preferable to the one often adopted of 
almost exclusively emphasising, possibly through "logo \& motto campaigns", attractiveness, considered as an objective in itself rather than the effect of well focused positioning and a strong and recognizable identity, as aimed at in the project for repositioning the city of Bologna.

In this perspective city branding is seen as a process integrated with the strategic choices of urban planning, on one side, and with the activities carried on by public and private institutions and the organized forms of civic society on the other.

To define the meaning of this phase of management of the brand, Simon Anholt introduced the concept of competitive identity characterized as a planning modality able to mobilize the strategies, the initiatives, the investments, the innovations and the communications developed by all the territorial components to convince the world that the city, for what it is doing, deserves a different and more positive image.

This process is based on three levels. (15)

A strategic approach in which all the components of the territory build up a clear, inspired and true narration of what the city and its population are and of the purpose towards which they are projected. A substantial approach that permits "stimulation and coordination of policies, strategies, investments, behaviours and above all innovations." Lastly a symbolic approach through symbolic actions that help to communicate in a pertinent and effective way what a territory does in the different sectors.

The strategic and at the same time substantial and symbolic approach to city branding adopted in Bologna is different from "traditional city branding dominant until a few years ago, characterized by coverage of two principal targets: tourists/visitors, on one side, and investors/business, on the other." (16) Not only are these two targets diversified into numerous sub-targets, thanks also to the opportunities offered by the new media, but it has been more and more necessary to keep in mind involvement of the local population and the residents, who have thus become a third macrocategory.

The municipality has assigned the integrated strategy of communication and the management of the brand of the city in relation to such different segments of the public to two organizations.

Bologna Welcome - the Destination Management Organization - is responsible for external communication of the city with the aim of attracting 
tourists, visitors, investments.

Urban Center Bologna - the Visitor and Participatory Center - is responsible for internal communications with the goal of creating the conditions for the active participation of citizens in the construction of the Bologna identity.

In the case of Bologna generative logo, the integrated communication strategy involves the use of a few logos internationally and the use of a growing number of logo moving from the istitutional to non-istitutional local level.

Until now, the international communication of the city of Bologna has used the logos City of Culture is Bologna and City of Food is Bologna (Figure 2).

Figure 2: Logos for City of Culture is Bologna and City of Food is Bologna.

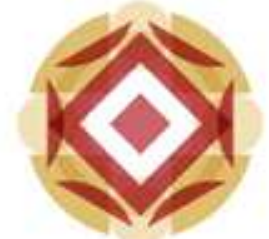

City of Food is Bologna

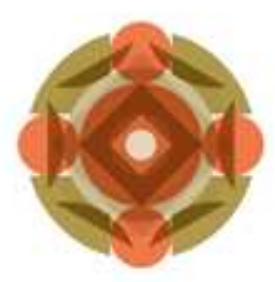

City of Culture is Bologna

Source: Image from the author.

At the institutional level the Municipality of Bologna has decided to comunicate all their initiatives within eight themes that illustrate the main political choices and values of the city administration: Metropolitan city, Economic Development, Welfare, School, Culture, Sustainability, Care of the City, Civic Innovation (Figure 3). 
Figure 3: Logos for the main political choices and values of the city administration.

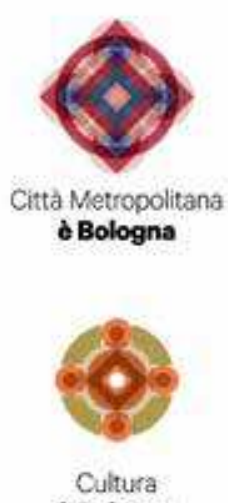

è Bologna
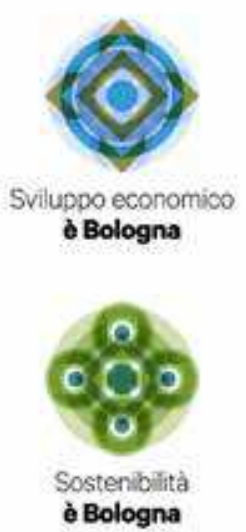

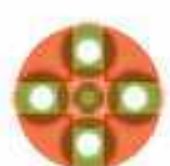

Benessere Bologna

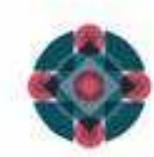

Cura della citta è Bologna
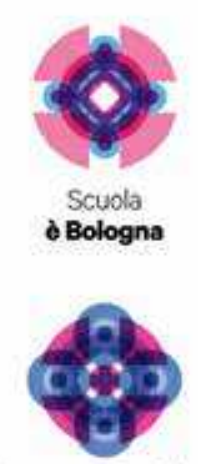

Innovazione civica è Bologna

Source: Image from the author.

At the local non-institutional level there is no quantitative limit to the use of the logo by associations, organizations and by individuals (figure 4).

Figure 4: Use of the logo by associations, organizations and by individuals.
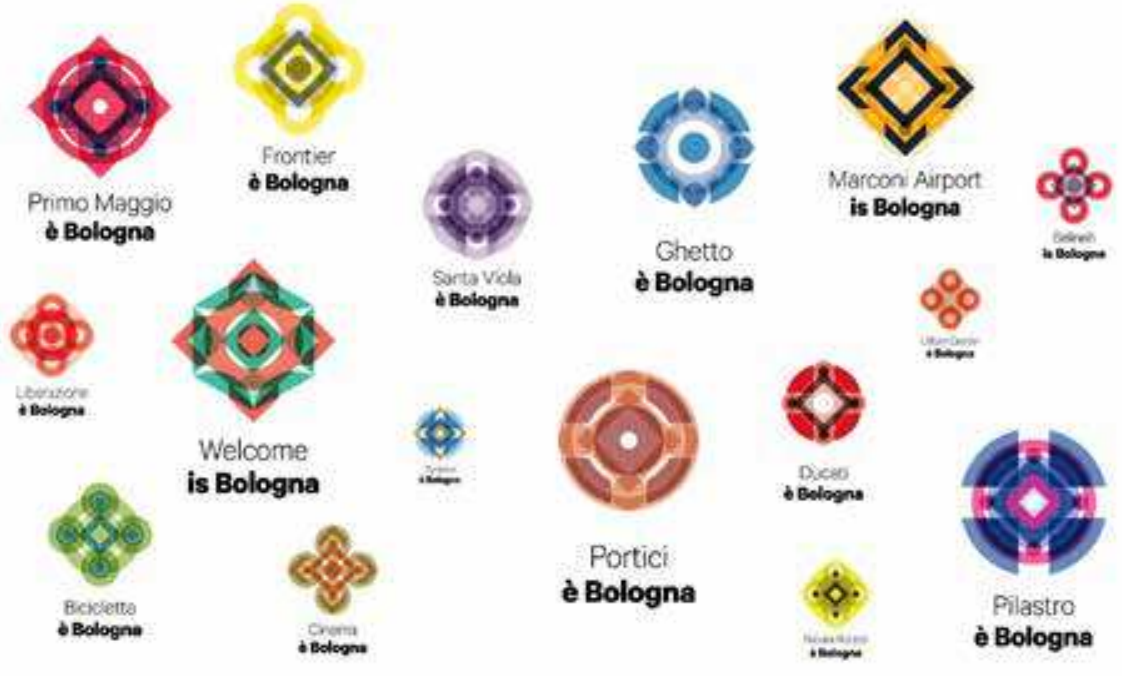

Source: Image from the author.

Hence the model adopted in Bologna identifies city branding as the conceptual, ideational and operational frame inside which not only are all the functions of city branding included, but also the two organizational and managerial structures of the project are identified, diversified for objectives and professionalism though operating in an integrated and strategically synergic way. 


\section{CONCLUSION}

This article focuses on the transition from place marketing to place branding, considered as the historic condition to develop the theoretic frame of the city branding which enables cities to build and communicate their own identities.

In this perspective city branding is seen as a process integrate with both the strategic choices of urban development and the activities carried on by institutions and the organized forms of civic society.

The Italian city of Bologna has adopted this theoretical frame for its Bologna City Branding Project that has developed its own methodology to define the process of construction and communication of the identity of the city.

Analysis of the perception of Bologna's image at a local, national and international level has been the first phase of the process of construction of the identity of the city, which constitutes the substance preceding the brand. This phase has been developed through different types of researches.

The indications deriving from the researches on both perceived and desired images of Bologna were summed up in the briefing that oriented the international contest for logo and pay-off.

We can say that the chosen logo can be considered distinctive, unique and conceived by lateral thinking.

In the judgment of the international jury the winner project has succeeded in "interpreting the briefing in all its requests, proposing a dynamic and open system of identity able to set going processes involving the whole population of Bologna, visitors and institutions. The system, proposing an open code, places at the centre of communication, as the principal subject, the city dweller, and proposes the city of Bologna not only as architecture and physical space, but as the result of a summation made up of individuals, firms, stories, ideas and visions" (17).

In fact the basis of this generative logo (or logo no-logo) is a system of writing replacing the graphemes of the Latin alphabet with abstract characterising signs: a new alphabet of geometric signs, based on five signs to be found in the tangible historical memories of the city of Bologna.

The construction of Bologna's visual identity is thus projected into a 
new and partly unexplored dimension. It is not only an adaptive and flexible system of identity, but - perhaps for the first time - also a participatory one.

Today the city of Bologna is committed to the second phase of the project: repositioning the city through valorisation, communication and management of the brand.

The model adopted in Bologna identifies city branding as the conceptual, ideational and operational frame inside which not only are all the functions of city branding included, but also two organizational and managerial structures operating in an integrated and strategically synergic way.

In the coming months we will see if all institutional and civic components of the city of Bologna will be able to use the generative logo in building an effective and participatory storytelling of the city.

\section{REFERENCES}

O'Leary, R., \& Iredale, I. (1976). The marketing concept: quo vadis? European Journal of Marketing, 10 (3), 156.

Grandi, R. (2010) Le città creative. II Mulino 6 (10): 1037-1044.

Grandi,R. Miani, M. (2006) L'impresa che comunica. Come creare valore in azienda con la comunicazione. Novara, Isedi - De Agostini.

Anholt, S. (2005) Some important distinctions in place branding. Place branding 1 (2), 117

Grandi, R. a cura di (1994) Semiotica al marketing. Le tendenze della ricerca nel marketing, nel consumo, nella pubblicità. Milano, Angeli.

Anholt, S. (2005) Some important distinctions in place branding. Place branding 1 (2), 120.

Braun, E. Zenker, S. (2010) "Branding a city - a conceptual approach for place branding and place brand management", paper presented at the 39th European Marketing Academy Conference, Copenhagen, 1-4 June: 3.

Grandi,R. Miani, M. (2006) L'impresa che comunica. Come creare valore in azienda con la comunicazione. Novara, Isedi - De Agostini.

Hanolt, S. (2007) Place branding: Is it marketing, or isn 't it? Place branding and Public Diplomacy: 0 (0), 1-6

Kavaratzis, M. (2004) From city marketing to city branding: Towards a theoretical framework for developing city brands Place Branding 1 (1). Rivas, M. ed. (2012) City Logo. Innovative place brand management. UrbAct CityLogo Baseline report. Brussels. 
Florian, B. (2002) "The city as a brand: Orchestrating a unique experience" in Hauben, T. Vermeulen, M. Patteeuw, V. (eds.) City branding: Image Building and Building Images. Rotterdam, Nai Uitgevers.

More information on all the phases of the development process of Bologna City Branding Process: http://www.urbancenterbologna.it/bologna-city-branding and https://www.youtube.com/watch?v=Hh u-c d3g8\&feature=youtu.be

Grandi, R. Neri, F. (2014) "Sentiment Analysis and City Branding" in B. Catania et al. (eds.), New Trends in Databases and Information Systems, Advances in Intelligent Systems and Computing. Berlin, Springer International Publishing, 339-350.

Rivas, M. ed. (2012) City Logo. Innovative place brand management. UrbAct CityLogo Baseline report. Brussels, 11-12.

Anholt, S. (2008) "The Importance of National Reputation" in Engagement: Public Diplomacy in a Globalised World. London, Foreign and Commonwealth Office, 3739.

Rivas, M. idem, 38.

--- "Minutes of the sessions of the Jury of the Bologna City Branding International Competition"

http://www.urbancenterbologna.it/images/Bolognacitybranding/verbale $\% 20$ giuria\%20bologna\%20city\%20branding_ing.pdf

Recebido em: 10/04/2014; Aceito em: 12/04/2014.

Esta obra foi licenciada com uma Licença Creative Commons.
Roberto Grandi, full time professor of Mass Communication at University of Bologna; Director of the International Master Marketing Communication and New Media (Bologna Business School). Former Visiting Professor at the Annenberg School of Communication (University of Pennsylvania), Stanford University, Brown University, Tongji University (Shanghai).

Scientific Coordinator of the Bologna City Branding Project (Urban Center Bologna). President of the College of China. Vice Rector at the University of Bologna (2000-2009). Deputy Mayor on Culture at the Municipality of Bologna (1996-1999). President of PromoBologna -Local development agency (2009-2011) and responsible for the City of Bologna Pavillon at the Shanghai Expò 2010.

Among his books: Come vincere le elezioni (2013) with Cristian Vaccari; La Comunicazione Pubblica (2007); L'impresa che comunica (2006) with Mattia Miani; I Mass Media fra testo e contesto (1994) in spanish Texto y contexto en los medios de comunicacion (1995); Come parla la pubblicità (1987); Radio e televisione negli Stati Uniti (Feltrinelli, 1980). 